\title{
Challenges of managing the emerald ash borer: What do managers want, and what can researchers tell them?
}

\author{
by C. J. K. MacQuarrie, ${ }^{1, *}$, K. Ryan², T. A. Scarr ${ }^{3}$ and K.L. Ryall ${ }^{1}$
}

\begin{abstract}
Hundreds of scientific articles and thousands of media reports have been written on the emerald ash borer (EAB) since its discovery in 2002. This incredible mass of information has proved to be overwhelming for forest health professionals who may not have the time or training to base management decisions on the best or most recent findings. At the same time the direction of the research community has at times diverged from that of the management community. This led us to ask two questions: 1) how well is the knowledge generated by researchers being translated to managers? 2) What research questions are most pertinent to managers? We conducted two independent studies where we elicited the knowledge, experiences and opinions of EAB managers and researchers using targeted interviews and a knowledge exchange workshop. We found that managers were unhappy and concerned with the pace of research and how findings are translated, and think that researchers are not addressing questions that are important to managers. They also report that jurisdictional issues have impeded the management of $\mathrm{EAB}$ in Canada. We make four recommendations to improve the relationship between forest pest managers and researchers and improve the practice of urban forest entomology in Canada.
\end{abstract}

Keywords: emerald ash borer (EAB), pest management, urban forestry, forest entomology, prevention, detection, risk assessment, control, restoration and rehabilitation, evaluation, research, education

\section{RÉSUMÉ}

Des centaines d’articles scientifiques et des milliers d’articles de journaux ont été rédigés sur l'agrile du frêne depuis sa découverte en 2002. Cette montagne d'information sest avérée être une masse écrasante pour les professionnels de la santé des forêts qui nont pas eu le temps ou la formation requise pour prendre des mesures de contrôle en fonction des meilleures ou des plus récentes découvertes. Parallèlement, lorientation de la communauté scientifique a divergé à certains moments de celle de la communauté chargée du contrôle. Cela nous amène à poser deux questions : 1) jusquà quel point les connaissances générées par les chercheurs sont-elles adéquatement transmises aux gestionnaires? et 2) Quelles avenues de recherche sont les plus pertinentes pour les gestionnaires? Nous avons entrepris deux études indépendantes au cours desquelles nous avons recueilli les connaissances, lexpertise et les opinions des gestionnaires et des chercheurs rattachés à lagrile du frêne au moyen d'entrevues dirigées et d’ateliers déchange de connaissances. Nous avons établi que les gestionnaires étaient insatisfaits et inquiets des progrès de la recherche et de la façon dont les découvertes étaient diffusées et qu'ils pensaient que les chercheurs ne répondaient pas aux questions qu'ils considéraient de première importance. Ils indiquaient également que les questions de compétence juridictionnelle avaient entravé le contrôle de l'agrile du frêne au Canada. Nous avons élaboré quatre recommandations pour améliorer les relations entre les gestionnaires responsables du contrôle des ravageurs et les chercheurs et pour développer la pratique de l’entomologie liée aux forêts urbaines au Canada.

Mots clés : agrile du frêne, contrôle des ravageurs, foresterie urbaine, entomologie forestière, prévention, détection, évaluation du risque, contrôle, restauration et réhabilitation, évaluation, recherche, éducation

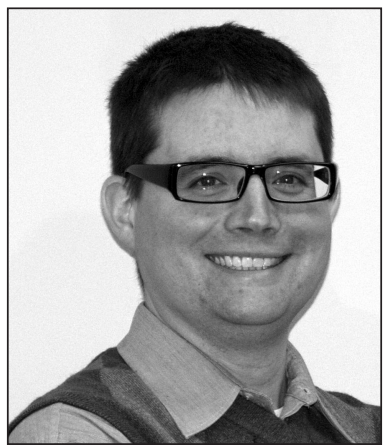

C. J. K. MacQuarrie

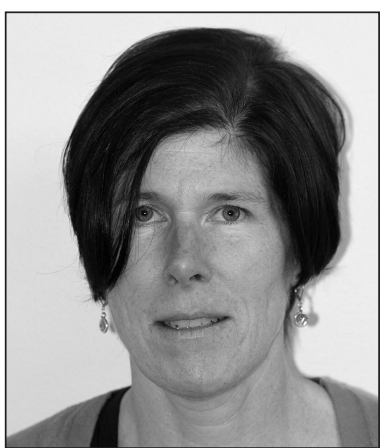

K. Ryan

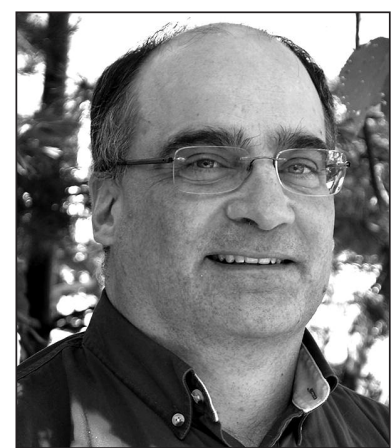

T. A. Scarr

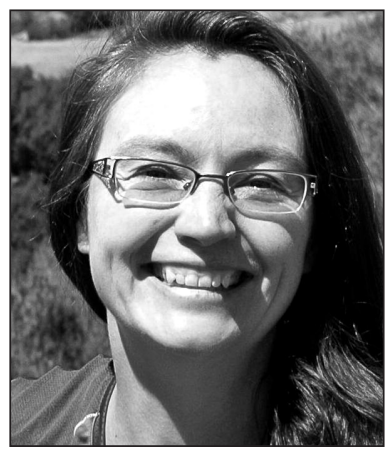

K.L. Ryall

\footnotetext{
${ }^{1}$ Natural Resources Canada, Canadian Forest Service, Great Lakes Forestry Centre, Sault Ste. Marie, Ontario, Canada, P6A 6V5; *corresponding author's email: chris.macquarrie@nrcan.gc.ca

${ }^{2}$ Silv-Econ Ltd. 913 Southwind Court, Newmarket, Ontario, Canada, L3Y 6J1

${ }^{3}$ Ontario Ministry of Natural Resources and Forestry, 70 Foster Drive, Suite 400, Sault Ste. Marie, Ontario, Canada, P6A 6V5
} 


\section{Introduction}

In early 2002, a forest pathologist investigating reports of reports of decline and mortality in ash, Fraxinus (Oleaceae), in Detroit, Michigan determined that the cause was an unknown, metallic green beetle. This spurred investigations in Windsor, Ontario that found similar ash mortality associated with the same metallic green beetle. Since the beetle was not previously known from ash in North America it was thought to be an introduced species. This hypothesis was confirmed when it was identified as Agrilus planipennis Fairmaire, a species native to eastern Asia. The common name "emerald ash borer" (EAB) was decided on in the summer of 2002 and the first report of the insect in North America was published that fall (Haack et al. 2002). EAB has since become the most significant forest health issue in eastern North America (Herms and McCullough 2014). EAB has killed tens of millions of trees, resulting in serious and extensive ecological and economic impacts. Responding to this threat has posed significant challenges to natural resource managers.

Since its discovery, researchers have produced a vast amount of scientific information on the biology, ecology and management of EAB. An even larger amount of practical and sometimes not-so practical information has also been produced by governments, public agencies, conservation groups and the pest management industry. Translating this information to private land owners and those who manage public lands has mostly been done using workshops (e.g., Ryall and Scarr 2012), public information meetings and websites (e.g., emeraldashborer.info and invasiveinsects.ca), but often those responsible for managing EAB have been left to their own devices to find information about $\mathrm{EAB}$, evaluate its content and then integrate that information into their response to EAB.

Emerald ash borer represents a unique challenge to natural resource managers and the research community. In Canada the management of forest pests has been the job of professionals employed by government or the forest industry. These managers are supported in their efforts by the research community at universities, within governments, and employed by industry, all of which conduct scientific research and develop products to guide and aid the management of pests. For simplicity, we refer to the former group as "managers" and the latter group as "researchers." In the past, the transfer of knowledge between managers and researchers was simple because these two groups are small and it is relatively easy to facilitate communication and achieve a degree of consensus as to how a pest should be managed and where research should be directed. Over many years, a working relationship had developed between federal and university researchers in Canada who generate the scientific information, and provincial pest managers who lead management programs. The response to EAB has challenged this traditional relationship. That is because, with the exception of regulatory controls by the Canadian Food Inspection Agency
(CFIA), the management of EAB in Canada is the responsibility of individuals and groups who are not part of the traditional networks of researchers and natural resource managers (e.g., urban forest managers, county foresters, and private landowners).

When EAB was found in North America almost nothing was known about the insect. Chinese scientists had documented EAB attacking white ash, Fraxinus americana L. and velvet ash, F. velutina Torr. in China but the accounts were not widely available outside of China (Wei et al. 2004). In contrast, between its discovery in North America in 2003 and the end of 2014 there was an almost exponential rate of increase in the number of published studies (Fig. 1) resulting in over 360 peer-reviewed papers in 132 different journals. Similarly, an internet search for the term "emerald ash borer" produces over half a million "hits", including over 7000 news articles and thousands of images. Left to wade through this sea of information are the natural resource managers and urban foresters who may have limited experience in assessing the quality of scientific data and informal advice, and a limited amount of time in which to collect information and make decisions. Moreover, accessing some of this information may be prohibitively expensive (e.g., $\$ 20-\$ 40$ to purchase a single article published in a peer-reviewed journal) and some information provided freely may be wrong, outdated, or presented in such a way as to advocate for a specific agenda (e.g., that of conservation groups or pest control operators).

As researchers and consultants we interact with managers tasked with responding to EAB. Our observation has been that some managers are very well-informed; others are

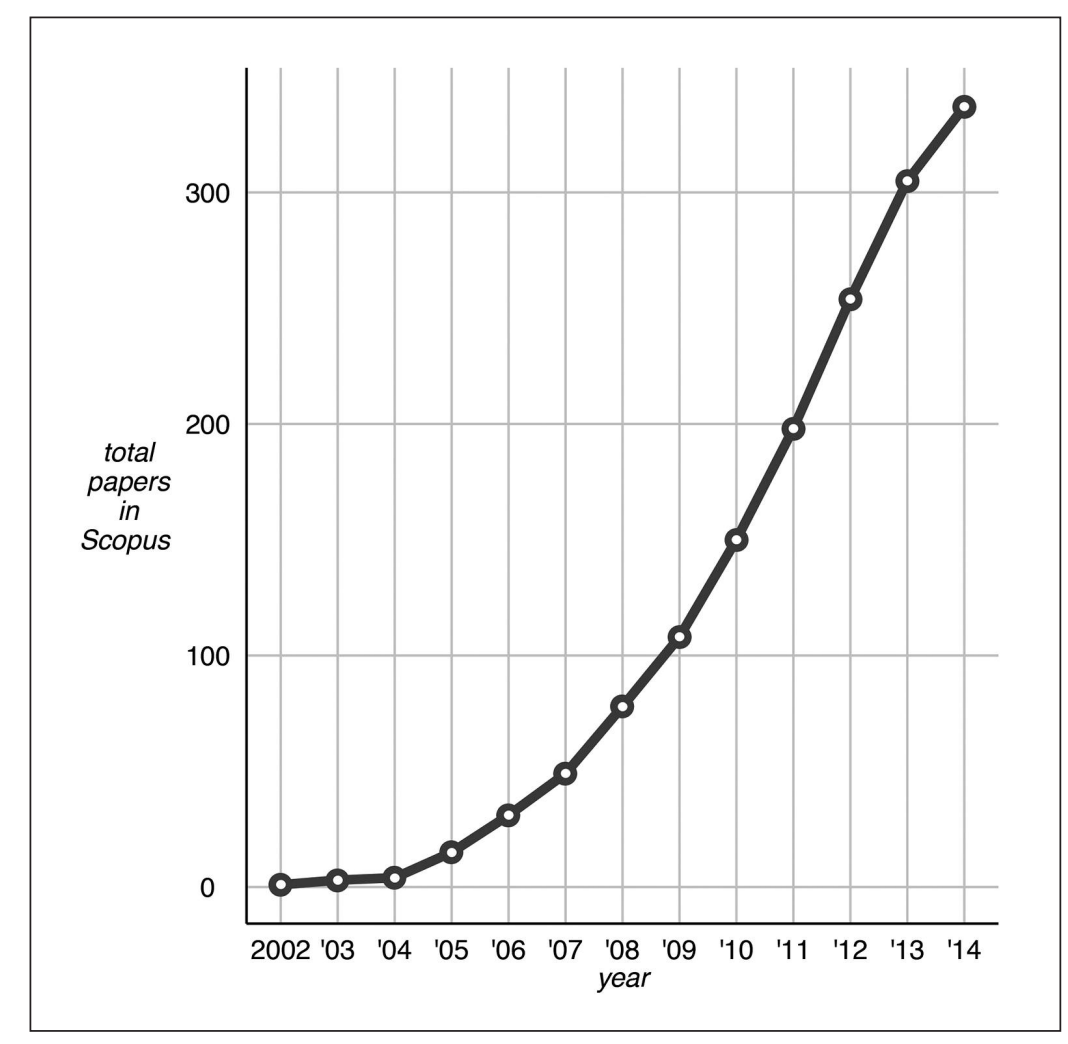

Fig. 1. The number of published studies on emerald ash borer experienced an almost exponential increase between 2003 and 2014. Data are the number of papers in the Scopus database returned for the search term "emerald ash borer" 
Table 1. Interview questions used in interviews to determine knowledge gaps and requirements

\section{Questions}

- What information about EAB do/did you need?

- What is the highest priority information that you need/needed?

- How/where did you get the information that you needed?

- How effective were you at getting it? (Were you able to get all of the information that you need/needed?)

- How could we have facilitated your ability to address EAB?

- What are you struggling with in terms of EAB?

- Do you have any suggestions of who else I should talk to?

informed but hold misconceptions about the insect; and still others know very little about the insect and its management. Conversely, we have also observed that the community of researchers is often unaware of the questions that managers are most interested in having answers to, and that research priorities are sometimes not well aligned with the questions that managers are asking. This led us to ask two questions: 1) how well is the knowledge generated by researchers being translated to managers? and, 2) what research questions are most pertinent to managers? To answer these questions we conducted two independent studies where we elicited the knowledge, experiences and opinions of EAB managers and researchers using targeted interviews and a knowledge exchange workshop.

\section{Methods}

Interviews

In the first study, Kathleen Ryan conducted a series of interviews between August and December 2012 with land managers and landowners responding to EAB. The list of interviewees was compiled to reflect the range of types of land managers in the province of Ontario and was comprised of those responsible for cities and towns, regional municipalities and counties, conservation authorities, provincial parks, First Nations lands, institutional lands (e.g., school boards, golf courses), and woodlot owners. In addition, professionals who support those responding to $\mathrm{EAB}$ were also interviewed (e.g., provincial forest health technicians, county foresters). The interviewees were from across Ontario and included those that worked within the area in Ontario where EAB was known to be established, and those that worked in areas where EAB had not been discovered. Potential interviewees were first contacted by email to schedule a phone interview. When potential interviewees did not respond to the initial attempt at contact, a maximum of two further attempts to contact were made, generally by telephone. Each interview consisted of a series of questions (Table 1), followed by an informal discussion on EAB management in which interviewees were free to ask questions or share their frustrations.

\section{Workshop}

In the second study, we organized a one-day workshop in October 2013 to which we invited researchers, land managers, regulators and other professionals with an interest in EAB. The workshop consisted of a morning of presentations on EAB and an afternoon "knowledge exchange" session. The afternoon knowledge exchange session consisted of a structured brainstorming session where attendees were asked for their knowledge and opinions on specific topics. To provide some context and organization to the session we adopted the structure of an idealized response to a new or emerging insect pest (Scarr 2012; Table 2). We prepared framing questions for each component to serve as a starting point (Table 2), but the participants were allowed to set their own course to the discussion so as to reflect their own specific interests and experiences. The attendees' remarks were recorded by facilitators who were also tasked with moderating the discussion. Before starting the session we informed the audience of the goal of the knowledge exchange session, and that their responses would be used to form the basis of this paper. The attendees were given 90 minutes to comment on up to four of the seven components, and an additional 10 minutes at the

Table 2: Components of a pest risk assessment and framing questions on emerald ash borer (EAB) used in the workshop knowledge exchange session

\begin{tabular}{ll}
\hline Component & Sample questions \\
\hline Prevention & - How do we prevent EAB from establishing in new locations? \\
Detection, Identification, Delimitation & - Why does EAB continue to spread? \\
Risk assessment & - What tools do you use to detect, identify and delimit EAB infestations? \\
& - What risks posed by EAB are we confident about? \\
Control & - What risks posed by EAB are poorly known? \\
Restoration and rehabilitation & - What control options for EAB are we not using \\
& - Wow will EAB damage be restored? \\
Evaluation & - What are the biggest impediments to restoration? \\
Research & - What are the challenges to implementing an EAB management plan? \\
&
\end{tabular}


end of the session to comment on any of the other components. The facilitators then summarized and presented all the contributions they received, after which the attendees were again asked to provide comments. All the information we obtained was then transcribed from the handwritten notes of the facilitators and summarized.

We reviewed all the responses captured during the interviews and knowledge exchange session and found that all took the form of either statements of fact, questions or suggestions. We further classified statements of fact as either accurate or inaccurate, based on how consistent they were with published scientific evidence or specific policies and best practices for the management of EAB. We also classified questions into two types, questions about managing EAB that had not been addressed by research we called "knowledge gaps." Questions about managing EAB that have been addressed by research were classified as a "lack of knowledge" (i.e., evidence that the participants were not aware that the information they wanted was available). Suggestions were those statements that defied classification into one of the other categories.

\section{Results}

Interviews

Sixty seven potential interviewees were contacted but only 44 provided comprehensive responses to the interview questions. The interviewees represented urban centres and regional municipalities (43\%), "point people" fielding questions about EAB (18\%), employees of conservation authorities or provincial parks (11\%), woodlot owners (11\%), institutional land managers (7\%), and managers of First Nations lands (5\%). The other $5 \%$ of interviewees had other positions such as forestry consultants or were employees of a non-governmental organization (NGO).

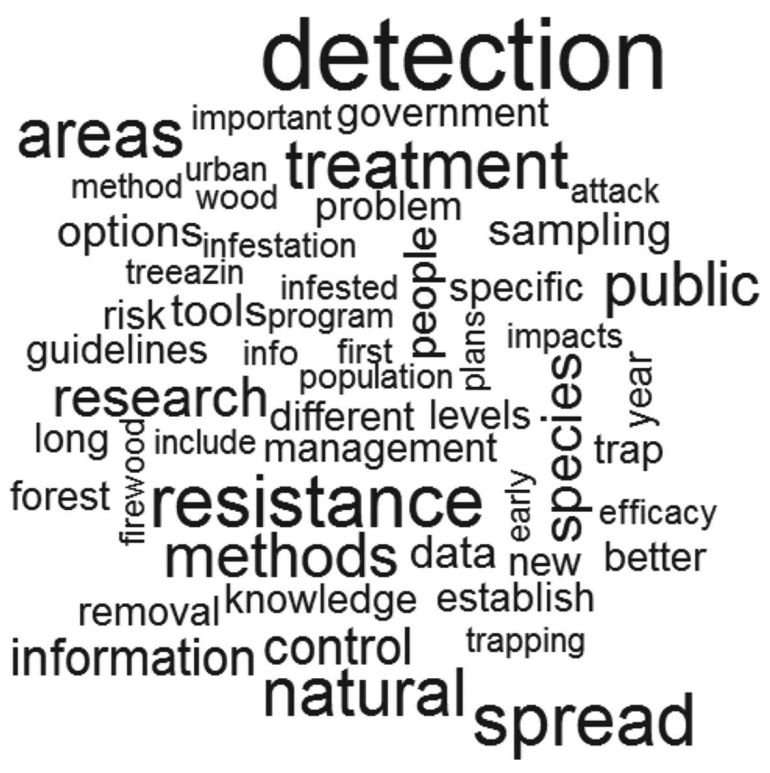

Fig. 2. Common words in the responses from the workshop participants. Words are sized relative to how often they were mentioned by the participants.

\section{Workshop}

A total of 91 people registered for the workshop. Almost all (97\%) were from Canada and worked in areas that were regulated for $\mathrm{EAB}$ in October 2013. Most attendees were employed by government (47\%), with the remainder split among the tree care industry (27\%; e.g., consultants, pest management firms, arborists, nurseries and gardens), universities (14\%), regional conservation authorities (9\%), and NGOs (2\%). A small number (10\%) did not attend the knowledge exchange session. We received responses to all seven components, but the number of the responses and detail provided by the workshop attendees varied. A qualitative analysis of all the responses indicated that most related to the "detection," "resistance," "treatment," and "spread" of EAB (Fig. 2).

\section{Prevention}

The participants in both studies were aware of the actions they could take within their own agency or at their level of government to prevent spread. They were also aware of the importance of early detection (Ryall et al. 2013), the challenges associated with it (Francese et al. 2013), and that infestations are typically much larger than expected once initially detected (Siegert et al. 2014). Participants also were aware of the high potential for natural spread (Muirhead et al. 2006) because of the large established population of EAB and the extensive availability of ash host trees with little or no host resistance (Anulewicz et al. 2006). They also knew that it was important for municipalities to have a tree inventory prior to the arrival of $\mathrm{EAB}$ and of the need to develop management strategies before infestation by EAB, including estimates of the likely costs (e.g., McKenney et al. 2012).

All participants were concerned about the lack of public knowledge about invasive species and aware of the need to foster an appreciation of the importance of healthy forests. They were familiar with the need for public education and agreed that a "do nothing" approach was to be avoided. For specific activities, the workshop attendees reported that outreach was effective and that the use of signage in infested areas was important. However, some of the interviewees reported that, despite a range of outreach strategies, some members of the public claimed to have never heard of EAB. Some participants expressed concern that awareness campaigns are only received by a portion of the population (to quote one of the interviewees: "we are informing the informed"). Similarly, the participants reported that it was difficult to raise the level of concern among members of the general public about the importance of $\mathrm{EAB}$, and that it was difficult to change attitudes among those who live outside the infested zone, or who live within the infested zone but have yet to be affected. For example, it was recognized that not only was more public awareness of the dangers of moving firewood needed, but also awareness of the risk from plants and wood products (e.g., crates, pallets, nursery stock) that may 
also carry EAB. It was noted that members of the public may assume that they do not have ash on their property, which may contribute to this lack of concern.

The participants identified a number of gaps in knowledge about prevention of EAB that do not appear to have been addressed by the research community. These were: 1) the mechanism responsible for the apparent resistance seen in blue ash (Fraxinus quadrangulata Michx. ), Manchurian ash (F. mandshurica Rupr.), and for the $1 \%$ of ash that appear to survive the initial wave of the infestation (e.g., Tanis and McCullough 2012); 2) if breeding or genetic modification could be used to produce ash resistant to EAB; 3 ) the role of proactive or prophylactic treatment of trees in delaying establishment; 4) how to identify which trees to treat, and how far in advance of EAB infestation to begin treatment; and, 5) which pathways are important for spread, and how satellite infestations form.

The prevention component elicited the most suggestions from the participants. They suggested that professionals should be enlisted in the crafting of public outreach campaigns in order to maximize the efficacy of these efforts by incorporating new methods of communication into outreach strategies (e.g., social media), developing curricula for schools, and developing tools to assess the impact of outreach programs on awareness. Other participants had suggestions to prevent the spread of $\mathrm{EAB}$, including providing free firewood at campsites; establishing and enforcing check points within quarantined zones to control the spread of infested material (including a "snitch line" to report offenders); and applying heavy penalties and fines against those moving infested material. They also remarked that it was important to ensure that the regulated areas in Canada cover the full range of where $\mathrm{EAB}$ is expected to be.

\section{Detection, Identification and Delimitation}

Most of the workshop participants were aware of the various tools and techniques that have been developed to facilitate detection, identification and delimitation of $\mathrm{EAB}$ infestations (e.g., Lelito et al. 2008, McCullough et al. 2009b, Poland et al. 2011, Ryall et al. 2011, Francese et al. 2012, Dominque et al. 2014, Legg et al. 2014). In contrast to the workshop participants, some interviewees, including those who would be responsible for EAB management, were not aware of the tools available to them. This difference may be explained by the fact that the all of the workshop participants had some familiarity with $\mathrm{EAB}$, whereas the interviewees had a wider range of backgrounds and experience in managing the insect. A few participants at the workshop suggested that guide books for tree pests were required, and that range data could be used to understand spread patterns for EAB. We interpreted this as an indication of lack of knowledge among the participants as there are numerous guides to insects and pests of hardwood forests, including one just on the Buprestidae of northeastern North

Perceived gaps

America (Paiero et al. 2012) and a number of papers have explored the issue of potential range, dispersal and spread of EAB (e.g., BenDor et al. 2006, Prasad et al. 2009, Taylor et al. 2010).

In reviewing the responses for this component it is apparent that managers have many questions about how and when to use the various tactics available to them (Table 3). We point out though that some questions (e.g., relating trap catch to insect density) are perennial questions in pest management that are not unique to the study of EAB. Regardless, it should be apparent that this component is a significant area of concern for managers of EAB. The participants suggest that work within this component could be improved if communication and collaboration among different levels of government was structured so as to avoid overlapping detection efforts and by encouraging volunteers to participate in detection programs. A central database of detection data for EAB in Canada was also suggested as a potentially useful tool for researchers.

\section{Risk assessment}

The participants were very familiar with the risk and impact caused by EAB infestations (Sydnor et al. 2007, Gandhi and Herms 2009, Moser et al. 2009, McKenney et al. 2012). Participants were well aware that EAB infestations appear to be small when first detected but are usually much larger than expected (Siegert et al. 2014); that infestations will progress rapidly once detected (Mercader et al. 2009); that EAB causes extensive mortality to ash (Knight et al. 2014); and, that management of infestations is extremely expensive (Sydnor et al. 2007, McKenney et al. 2012). Most participants were aware that much of southern Ontario is regulated for EAB. The only indications of a lack of knowledge in this section were from two statements: 1) a request for forest inventory tools for forests affected by EAB; and, 2) a question if inventories are necessary for assessing the risk of EAB. This was troubling to us as we expected that forest managers would know that the tools to conduct a forest inventory are well developed and widely available (e.g., i-Tree Canopy 2015, Neighborwoods 2015 ) and it should be readily apparent that an inventory is

Table 3: Perceived knowledge gaps according to managers, in the detection and delimitation of emerald ash borer

\section{Methodological}

Optimal spacing for sampling, trapping

Failure rate for traps

New traps and techniques

Efficacy of green/green leaf volatile vs. purple/manuka oil trapping methods

\section{Operational}

Cost effectiveness, economics of methods

How to select appropriate methods for specific needs, conditions

Logistics of implementation

What are performance indicators for surveys
Analytical

Relation of trap catch to density

Comparison of trapping methods

\section{Research and Development}

What defines an early detection

New traps, improve current traps

Methods for cut lumber

Novel methods (e.g., unmanned drones) 
required for a robust pest risk assessment. However, the interviews found that managers, especially those in smaller municipalities or on institutional land, may have limited knowledge of how to conduct a risk assessment (Barker and Kenney 2012).

Some questions from the workshop participants addressed the risk of $\mathrm{EAB}$ moving to non-ash hosts (i.e., once the ash resource has been consumed). The host range of EAB has been known since 2008 (Anulewicz et al. 2008) and clearly demonstrated that non-ash genera would not be attacked and cannot support development of EAB populations. Moreover, these facts have been well-publicised, and are a common feature of news reports and outreach documents. A recent study has shown that EAB will attack the white fringetree, Chionanthus virginicus L. (Cipollini 2015). However, the study reports observations that were made after our interviews and workshop had concluded, and so our participants would have been unaware of this finding. Thus, we are unsure why questions related to EAB's potential hosts continue to persist. That they do supports the observation that outreach activities intended to educate managers and the general public may not be as successful as was hoped.

Many of the participants expressed the view that the impact and risk of $\mathrm{EAB}$ in natural areas had been overlooked. In particular, they were concerned about persistence of ash on the landscape and the effect of tree loss on soil erosion, water quality, aquatic habitats and forest biodiversity. These questions were raised both in the context of losses caused by EAB mortality in wooded areas, rural forests and in the contiguous forest, but also due to tree removal during pre-emptive harvest of ash from woodlots (Streit et al. 2012). Gandhi and Herms (2009) addressed some of these questions for forests in the United States, but work in Canada has only recently begun to look at long-term effects (Nisbet 2014, Aubin et al. submitted ${ }^{1}$, Kreutzweiser et al. unpublished data $\left.^{2}\right)$. Other questions addressed the potential for altered population dynamics of the insect in other regions (e.g., western Canada) under a changing climate, the effect of tree resistance, and if over time EAB may begin to exhibit dynamics similar to that of other invasive pests (e.g., Dutch elm disease).

Risk assessment is a broad topic and in defining the parameters of the workshop we intended it to be limited to the risk of EAB to forest health. However, some of the participants interpreted "risk assessment" to mean the risks associated with controlling and managing EAB and so we captured a number of comments and questions that fell under this interpretation. Some participants wondered about the distribution and abundance of ash on the landscape and why research was not looking at pathways and how to prevent the spread of EAB. Other participants believed that EAB was, or is, attacking both walnut and hickory, and that EAB will "mutate" to attack other tree genera once ash has become extirpated. These questions are all areas that have been welladdressed in the scientific literature. For instance, data on forest composition is available from federal and provincial gov-

\footnotetext{
${ }^{1}$ Aubin, I., Cardou, F., Ryall, K., Kreutzweiser, D. and Scarr, T. Ash regeneration dynamics after EAB outbreaks: Any hope?

${ }^{2}$ Kreutzweiser D, Aubin I, Venier L, Ryall K, (Natural Resources Canada Canadian Forest Service) and Sibley P (University of Guelph).
}

ernments; there have been numerous studies on pathways and spread of EAB in Canada and the United States (e.g., BenDor et al. 2006, Yemshanov et al. 2012), and as we discussed above, the potential host range of $\mathrm{EAB}$ was examined some time ago (Anulewicz et al. 2008). That these questions persist suggests that all relevant data are not being considered when managers are assessing the risk of EAB to their forests. However, there are legitimate knowledge gaps between what managers require and what the research community has produced. The participants requested more information on spread and dispersal of EAB in order to more accurately predict associated risks. In particular, they wondered if urban centres act as "hubs" for new infestations by EAB. Others asked why EAB's biology and dynamics appear to be so different in North America compared to in its' native range (a recent publication by MacQuarrie and Scharbach 2015 has provided a partial explanation to this question). Lastly, some participants suggested that risks associated with the management of dead trees in the urban landscape had not been addressed, and in particular, the health and safety risks associated with the removal of dead ash.

\section{Control}

In both studies, respondents had good familiarity with the type of control options used in Canada (i.e., insecticides, biological control and silviculture) and they were aware of methods not widely used in Canada (e.g., girdled trap trees; McCullough et al. 2009a). However, they were not necessarily aware of the specific products and tactics available to them (i.e., which insecticides were registered for use in Canada). They were aware that removal of trees is not always the most economical option (McKenney et al. 2012).

There were a large number of questions about the tactics managers could use to control EAB populations (Table 4). When we examined the trends in these questions, we found that many seem to reflect a desire for more tactics to use against EAB. These tactics would include alternative insecticide options and classical biological control. The participants also wanted more information on the practical aspects of selecting, implementing, and evaluating among the set of tactics available for use in Canada. Included in this is the desire for prescriptions on how and when to apply different techniques, and an assessment of the effectiveness and environmental impacts of the current options. We also note here that the participants expressed frustration that recommendations have changed from year-to-year (e.g., the dose, timing, or frequency of application of insecticides) and that others questioned why research done in the United States on control options could not be directly applied to Canada. We address these questions in the discussion.

\section{Restoration and rehabilitation}

The participants exhibited little specific knowledge on the role of restoration and rehabilitation following EAB. This suggests that post-EAB rehabilitation is poorly understood among the land managers in our sample, that the issue is not a concern, or that other issues (e.g., managing infestations) are more pressing. Regardless, the participants thought it was important to include the public in this component, and identified that there is lack of information on managing forests and woodlots post-EAB. In this vein, some participants 
Table 4: Perceived knowledge gaps according to managers, in control and management of emerald ash borer (EAB).

Perceived gaps

Methodological

Application techniques for insecticides

New insecticide formulations

How to prioritize treating versus removing trees in urban and natural stands.

\section{Operational}

Optimal timing of application for insecticides

Criteria for decreasing treatment programs as populations decline

Efficacy, specificity and non-target impacts of biological control agents

Removal criteria for infested trees (size, proximity to infestation)

How to integrate control options

Decision support tool for determining when to treat and when to remove tree

Length of time to treat a tree with TreeAzin in different conditions

Best management practices for different land types Predictive model for EAB spread and population growth rate and stages of EAB infestation/post infestation

\section{Research and Development}

Environmental impacts of insecticides

Likelihood that EAB will develop resistance to insecticides pheromones, mating disruption)

How long until classical biological controls can manage EAB?

Methods to enhance tree health different landscapes and environmental conditions

\begin{abstract}
Analytical
How to assess and evaluate success of control programs

How to assess risks in decision making when developing management strategies

How to account for the green infrastructure value of a tree
\end{abstract}

Phytotoxicity and long-term impacts on trees from repeated application of insecticides

Exploration of novel control options (Bt, viruses, nematodes, endophytes, sterile males,

Ash decline mechanics - how long does it take for a dead ash to become a hazard in

wanted advice on conserving and managing residual and regenerating ash, including doing so in protected areas where the full set of control options may not be available. Related to these issues were questions about how forest communities will behave after ash mortality, and if it will be safe to reintroduce ash to areas where it has been extirpated. There were also operational concerns around implementing restoration programs (e.g., determining goals, quantify costs, disposing of dead trees).

\section{Evaluation}

The participants were aware of the need to evaluate their activities in response to $\mathrm{EAB}$, and to engage in quality assurance and quality control testing when tactics are implemented. However, it appears that some of the participants were unclear about how programs are, or should be, evaluated. For instance, the participants wondered how the effectiveness of quarantine activities was determined; what standards there were for the efficacy of control measures; and, how to evaluate the impacts of mortality and management on ecosystem functioning. They considered it necessary to network with a variety of stakeholders (e.g., the public, municipalities, other levels of government) in order to evaluate the success of their programs, and that evaluation would be easier if the barriers between different levels of government were reduced. When considering their own programs they were aware that it was necessary to evaluate new tactics and to integrate these into their management plans.

\section{Research}

Here we focus on the responses that we received that addressed how the activity of research was perceived by the participants. In general, the participants considered that research activities were useful, particularly with respect to topics related to sampling and control options (Tables 3 and 4). However, there also seemed to be two predominate, underlying themes in the comments: 1) an apparent lack of knowledge about how scientific research is done and, 2) a lack of understanding about how new scientific information is disseminated. We discuss the consequence of these themes in more detail in the following section. The workshop participants and interviewees wanted to be better informed about current research on $\mathrm{EAB}$, and the status of ongoing projects. They suggested that information should be integrated and distributed to interested stakeholders on a regular basis, for instance, via a website or in a forum where they could post questions. They also suggested that there was a need for better collaboration between researchers and governments, municipalities and other stakeholders.

\section{Discussion}

The volume of comments we received from both studies (Fig. 2) made it a difficult task to extract general trends. We received many specific recommendations from managers for research topics (e.g., Tables 3 and 4 ) and identified some areas where communication and dissemination of research could be improved. Our impression is that the community of $\mathrm{EAB}$ managers understands the biology and ecology of the insect. However, this comprehension was not universal. For example, there was some misunderstanding about which trees $\mathrm{EAB}$ attacks. We argue that this reinforces the need for more education, for the simple reason that if such a basic piece of information is not known, it indicates that managers are not as knowledgeable as researchers have assumed them to be. If 
that is true, then it will limit how effective knowledge transfer activities (like workshops) can be because it means researchers and managers are not on the same footing.

In summarizing the comments we received on the various components, we found four general complaints about the relationship between researchers and managers. Managers were: 1) unhappy with the pace of research; 2) concerned about how the findings of research are translated; and, 3) think that researchers were not addressing questions that are important to managers. A fourth complaint, that jurisdictional issues have impeded the management of EAB in Canada, was also frequent. This last item does not directly relate to the relationship between researchers and managers. However, the complaint seemed relevant, in part because researchers and EAB managers usually work for different levels of government, which often have different priorities.

In response to the first complaint, we point out that the pace of research on EAB has been rapid (Fig. 1). That managers perceive the pace of research otherwise suggests that perhaps the information needs of managers are not being completely met by the research community. That said, the pace of research on EAB appears to be levelling off (Fig. 1) which is either indicative of a maturing of the field, or that research priorities are beginning to shift away from EAB. Regardless of the cause, the effect is that managers perceive the progress of research as slow, when perhaps it is just proceeding in a different direction. Understanding why managers think the pace of research is slow may help suggest new areas of research, or better ways of translating existing research to managers.

Complaints about the translation of research seem to be rooted in the desire of managers for definitive answers (see "control" and "research" sections). We argue that as science understands the insect better, it is reasonable to expect recommendations to change over time. For instance, research on trapping $\mathrm{EAB}$ has changed the recommendations from purple traps to two versions of a green trap, then the addition of a Manuka/phoebe oil attractant, then a switch to a (3Z)hexenol attractant and more recently to a (3Z)-lactone pheromone (reviewed in Ryall 2015). That these recommendations are changing frequently is a suggestion that there is still much to learn about EAB. Thus we find it difficult to reconcile the demand for more research, with a desire for definitive answers. We do agree that there is a challenge with how new and ongoing research is communicated to managers. This may be because new knowledge about EAB is currently being reported at scientific conferences and in scientific journals but these conferences are not attended nor are these journals read by managers of EAB.

Education for managers about EAB in Canada has so far focussed on workshops. Our experience is that these workshops are worthwhile and well-attended. However, workshops are only capable of reaching a limited audience. For instance, in Ontario, many governments place restrictions on travel that make it difficult for employees to attend workshops being held outside their own municipality. Alternately, some managers may be simply unaware of EAB and only start attending workshops after the insect becomes a problem on their lands. Workshops also do not address the problem where managers do not have regular, direct contact with researchers. As well, not all researchers are adept at commu- nicating their knowledge in a way that is clear and understandable to those outside their field, or to groups that may lack the same technical background. The results of our two studies suggest a better method is required to educate managers about $\mathrm{EAB}$.

In reviewing many of the knowledge gaps that were identified by managers, we noted that a great many were being addressed by active research programs, either in Canada or in the United States. For instance, recent studies on resistance in native ash (Whitehill et al. 2014) would seem to address some of the questions raised around prevention of EAB infestations. This suggests that researchers are anticipating some of the needs of managers, but also that managers are not aware of what researchers are doing. We argue that improving communication between managers and researchers would help better direct the course of research on EAB. We acknowledge that it is inevitable some of the priorities of researchers will be different from those of managers. However, in order for there to be an effective relationship between the two groups, there must be a minimum amount of overlap between those different priorities. Currently, our research suggests that this has not occurred. Related to the direction of research programs, many of the participants also reported that a lack of funding has impeded the research effort against EAB. In fact, the issue of insufficient funding was raised as a limiting factor for activities within each of the components. A lack of resources to research and manage pests is a perennial concern and not unique to the response to EAB. However, when deciding how to allocate the resources that are being allocated to EAB, we argue that some of the research desired by managers (e.g., Tables 3 and 4) is different from the research that is being supported by funding agencies and governments.

Many of the comments addressed jurisdictional issues and focussed on the need for improved monitoring and enforcement of existing quarantine regulations. In Canada, quarantine of EAB is a federal responsibility and to date has focused on reducing the spread at large spatial scales (i.e., between regions or provinces). Provinces and cities are generally concerned with the loss of valuable street trees, spread into natural areas, and movement between municipalities. At times, the goals of the different levels of government have not been compatible. Moreover, within the regulated zone, different levels of government have assessed the risk of EAB differently and responded with a wide variety of tactics that have not been coordinated. In a similar vein, we argue that public communication about the risks of $\mathrm{EAB}$ has been done in a rather piece-meal fashion. Various groups and different levels of government have instigated their own information campaigns but these have not been coordinated. The results of our studies suggest that there is room for improvement in this area.

\section{Recommendations}

At the end of our knowledge exchange sessions it was apparent to us that research and management of EAB in Canada was at a crossroads. The observations of our participants give us an idea of how our journey to this point has progressed and some guidance as to which direction we should choose. To help with this decision, we make the following recommendations. 
1) That researchers review the current state of knowledge on $E A B$. To improve the management of EAB, it is important to assess what we know about the insect and its management. We make this recommendation knowing that it has already been met to a certain extent. Over the past twelve years a few subject-specific reviews (Crook and Mastro 2010, Crook et al. 2014) and one general review (Herms and McCullough 2014) have been published. Earlier this year a series of comprehensive reviews were published (MacQuarrie et al. 2015 and citations therein) that assessed the state of knowledge on EAB. We hope that by assessing what questions have been answered, and what questions still remain for EAB, that these reviews will guide future research. We also hope that managers of $\mathrm{EAB}$ will use these works as a resource to learn more about the insect.

2) That the capacity to do extension work and technology transfer for forest health issues be expanded. It is apparent that the needs of managers and the activities of researchers are not well linked. These links could be improved by the creation of an extension agency dedicated to forest management (Kenney 2003). In the past, management decisions for forest pests were the dominion of governments and industry. However, today forest management decisions for $\mathrm{EAB}$, and other forest pests, are more frequently being made by municipalities and private landowners. This shift has resulted in a state of affairs similar to what has existed for agricultural producers and rural landowners for decades. There, the relationship between producers, landowners and researchers is mediated by extension agencies that serve to translate research results into advice and guidance. No similar system exists in Canada for forests; however such a system does exist in the United States in the extension departments at land grant universities. Kenney (2003) advocated for the creation of extension agencies for urban forestry under the direction of the various provincial ministries. However, we see no reason why universities, NGOs, or even private industry could not fill this role. Regardless of the how an extension agency is comprised, we argue that the management of forest health issues in Canada, including $\mathrm{EAB}$, would benefit from the existence of extension agencies.

3) That the roles of different levels of government in the management of urban forest pests be formalized. Many of the participants in the workshop expressed frustration with how the response to $\mathrm{EAB}$ has not been consistent among different levels of government. This seems to reflect some long-standing frustration with how the responsibility for urban forests is delegated in Canada (Kenny 2003). There also appeared to be some confusion as to which level of government is responsible for dealing with urban forest issues. This frustration and confusion may stem from the fact that managers in Canada have been able to observe the simultaneous response to $\mathrm{EAB}$ in the United States where federal agencies have a very different role in the management of forests. It may be that Canadian managers expected a similar level of response from their federal agencies. We do not advocate for a similar system in Canada. However, we do advocate that it would be helpful to establish a formal and agreed-upon structure within which information can be shared, one that clearly outlines the responsibilities of each level of government under existing legislation, at least as those roles relate to the management of urban forest pests. Multiple levels of government, the tree care industry and the public all have a role to play in managing pests in the urban forest. One lesson we can learn from $\mathrm{EAB}$ is that good pest management decisions can be made if these groups can work together efficiently.

4) That the capacity for urban forest pest research and education be expanded. In Canada, forest pest management, and specifically forest entomology, is taught at the undergraduate level at just a handful of universities. Ontario exemplifies the current state of university-level research: of 73 professors with research programs in entomology at Ontario universities, three indicate "forestry" is part of their research program and of these only one has forest pest management as their major focus (Entomological Society of Canada 2014). In comparison, there are at least five professors with research programs in agricultural entomology, and ten professors with programs in arthropod systematics (Entomological Society of Canada 2014). Outside of universities, the federal government maintains a laboratory in northern Ontario with a staff of forest entomologists but its mandate has not included urban forest pest issues. The provincial government also maintains a laboratory in northern Ontario but it has no staff or mandate to address urban forest pest issues. Thus, in Ontario, there is no significant capacity to do research on forest entomology in the large urban areas, nor is there significant capacity to train forest pest managers. This is in spite of the fact that the province has experienced two of the most significant invasive insect introductions to Canada: EAB and the Asian longhorned beetle, Anoplophora glabripennis (Motschulsky) (Carter et al. 2012). However, Ontario is not unique in this regard, as the lack of research capacity extends to most of the major urban centres in Canada. For instance, Canada's three major ports of entry (Vancouver, Montreal and Halifax) all have large research communities (including two of Canada's top research universities), but have almost no research capacity to respond to new threats from invasive urban forest pests at the university, provincial, or federal level. Others have proposed that some of these issues could be addressed by the creation of a federal or provincial research agency specifically dedicated to urban forestry (Kenney 2003, Barker and Kenney 2012) similar to what exists in the United States. Regardless of how this issue is addressed, one lesson we should learn from $\mathrm{EAB}$ is that a rapid response by researchers is required to develop the tools for managers to combat a newly discovered pest. In Canada we lack the research capacity to respond to most threats with the appropriate level of response.

\section{Conclusions}

More than a decade has passed since EAB was discovered in Canada, and more than two decades have passed since its introduction to North America (Siegert et al. 2014). Given that there is typically a lag between introduction and detection of new invasive alien species, it is possible that the next invader has already been introduced to our forests. Much work has been done to address the needs of managers responding to the losses caused by EAB but the information we have reported would suggest that a great deal of work still needs to be done. This work should be directed towards research addressing the needs of managers of ash forests. However, there is an underlying issue of organizational capacity to respond to urban forest threats in Canada. Here, the most pressing need seems to be the need for an agency to 
translate research to those that need it the most. Currently, organizational structures and differing priorities among levels of government have created barriers between groups. We argue that effort is required here as well to simplify these relationships so that the flow of information is not impeded.

\section{Acknowledgements}

We thank the participants in the workshop and the interviewees who consented to share their views with us, and D. Dutkiewicz, J. Fidgen, B. Lyons, D. Nisbet, D. Rowlinson, and L. van Seggelen for their assistance during the workshop session. This work was funded by the Ontario Ministry of Natural Resources and Forestry, Natural Resources Canada and the Natural Sciences and Engineering Council of Canada (R\&D Fellowship to K. Ryan)

\section{References}

Anulewicz, A.C., D.G. McCulloughand D.L. Miller. 2006. Oviposition and development of emerald ash borer (Agrilus planipennis) (Coleoptera: Buprestidae) on hosts and potential hosts in no-choice tests. Gt. Lakes Entomol. 39: 99-111.

Anulewicz, A.C., D.G. Mccullough, D.L. Cappaert and T.M. Poland. 2008. Host range of the emerald ash borer (Agrilus planipennis Fairmaire) (Coleoptera : Buprestidae) in North America: Results of multiple-choice field experiments. Environ. Entomol. 37(1): 230-241. doi: 10.1603/0046-225X(2008)37.

Barker, J.E. and A.W. Kenney. 2012. Urban forest management in small Ontario municipalities. For. Chron. 88(2): 118-123. doi: 10.5558/tfc2012-027.

BenDor, T.K., S.S. Metcalf, L.E. Fontenot, B. Sangunett and B. Hannon. 2006. Modeling the spread of the emerald ash borer. Ecol. Modell. 197(1-2): 221-236. doi: 10.1016/j.ecolmodel.2006.03.003.

Carter, M.E., M.T. Smith, J.J. Turgeon and R.G. Harrison. 2012. Analysis of genetic diversity in an invasive population of Asian longhorned beetles in Ontario, Canada. Can. Entomol. 141(6): 582-594. doi: 10.4039/n09-026.

Cipollini, D. 2015. White fringetree as a novel larval host for emerald ash borer. J. Econ. Entomol. doi: 10.1093/jee/tou026.

Crook, D.J. and V.C. Mastro. 2010. Chemical ecology of the emerald ash borer Agrilus planipennis. J. Chem. Ecol. 36(1): 101-112. doi: 10.1007/s10886-009-9738-x.

Crook, D.J., J.A. Francese, M.L. Rietz, D.R. Lance, H.M. HullSanders, V.C. Mastro, P.J. Silk and K.L. Ryall. 2014. Improving detection tools for emerald ash borer (Coleoptera: Buprestidae): Comparison of multifunnel traps, prism traps, and lure types at varying population densities. J. Econ. Entomol. 107(4): 1496-1501. doi: 10.1603/EC14041.

Domingue, M.J., D.P. Pulsifer, A. Lakhtakia, J. Berkebile, K.C. Steiner, J.P. Lelito, L.P. Hall and T.C. Baker. 2014. Detecting emerald ash borers (Agrilus planipennis) using branch traps baited with 3D-printed beetle decoys. J. Pest Sci. doi: 10.1007/s10340-014-0598-y. Entomological Society of Canada. 2014. Directory of Entomological Education in Canada, $7^{\text {th }}$ Edition. Web. Accessed 19 May 2015. http://www.esc-sec.ca/direntomology.php.

Francese, J.A., I. Fraser, M.L. Rietz, D.J. Crook, D.R. Lance and V.C. Mastro. 2012. Relation of color, size, and canopy placement of prism traps in determining capture of emerald ash borer (Coleoptera: Buprestidae). Can. Entomol. 142(6): 596-600. doi: 10.4039/n10-041.

Francese, J.A., M.L. Rietz, D.J. Crook, I. Fraser, D.R. Lance and V.C. Mastro. 2013. Improving detection tools for the emerald ash borer (Coleoptera: Buprestidae): Comparison of prism and multifunnel traps at varying population densities. J. Econ. Entomol. 106(6): 2407-2414. doi: 10.1603/EC13013.

Gandhi, K.J.K. and D.A. Herms. 2009. North American arthropods at risk due to widespread Fraxinus mortality caused by the
Alien Emerald ash borer. Biol. Invasions 12(6): 1839-1846. doi: 10.1007/s10530-009-9594-1.

Haack, R.A., E. Jendek, H. Liu, K.R. Marchant, T.R. Petrice, T.M. Poland and H. Ye. 2002. The emerald ash borer: A new exotic pest in North America. Newsl. Michigan Entomol. Soc. 47(3\&4): 1-5.

Herms, D.A. and D.G. McCullough. 2014. Emerald ash borer invasion of North America: history, biology, ecology, impacts, and management. Annu. Rev. Entomol. 59: 13-30. doi: 10.1146/annurevento-011613-162051.

i-Tree Canopy. 2015. i-Tree Software v 5.0. Web. Accessed 9 Feb 2015. https://www.itreetools.org/.

Kenney, W. A. 2003. A strategy for Canada's urban forests. For. Chron. 79(4): 785-789. doi: 10.5558/tfc79785-4.

Knight, K.S., B.P. Flash, R.H. Kappler, J.A. Throckmorton, B. Grafton and C.E. Flower. 2014. Monitoring ash (Fraxinus spp.) decline and emerald ash borer (Agrilus planipennis) symptoms in infested areas. USDA For. Serv. Gen. Tech. Rep. NRS-139.

Legg, D.E., J.G. Fidgen and K.L. Ryall. 2014. Resampling simulator for the probability of detecting invasive species in large populations. J. Softw. Eng. Appl. 7(6): 498-505. doi: 10.4236/jsea.2014.76046.

Lelito, J.P., I. Fraser, V.C. Mastro, J.H. Tumlinson and T.C. Baker. 2008. Novel visual-cue-based sticky traps for monitoring of emerald ash borers, Agrilus planipennis (Col., Buprestidae). J. Appl. Entomol. 132(8): 668-674. doi: 10.1111/j.1439-0418.2008.01308.x.

MacQuarrie, C.J.K. and R. Scharbach. 2015. Influence of mortality factors and host resistance on the population dynamics of emerald ash borer (Coleoptera: Buprestidae) in urban forests. Environ. Entomol. 44(1): 160-173. doi: 10.1093/ee/nvu011.

MacQuarrie C.J.K., T.A. Scarr and K.L. Ryall. 2015. The science of emerald ash borer (Coleoptera: Buprestidae): where are we after 10 years of research?. Can. Ent. 147(3): 249-251. doi: 10.4039/ tce.2015.19.

McCullough, D.G., T.M. Poland, A.C. Anulewicz and D. Cappaert. 2009a. Emerald ash borer (Coleoptera: Buprestidae) attraction to stressed or baited ash trees. Environ. Entomol. 38(6): 1668-1679. doi: 10.1603/022.038.0620.

McCullough, D.G., T.M. Poland and D. Cappaert. 2009b. Attraction of the emerald ash borer to ash trees stressed by girdling, herbicide treatment, or wounding. Can. J. For. Res. 39(7): 1331-1345. doi: 10.1139/X09-057.

McKenney, D.W., J.H. Pedlar, D. Yemshanov, D.B. Lyons, K.L. Campbell and K. Lawrence. 2012. Estimates of the potential cost of emerald ash borer (Agrilus planipennis Fairmaire) in Canadian municipalities. Arboric. Urban For. 38(3): 81-91.

Mercader, R.J., N.W. Siegert, A.M. Liebhold and D.G. McCullough. 2009. Dispersal of the emerald ash borer, Agrilus planipennis, in newly-colonized sites. Agric. For. Entomol. 11(4): 421-424. doi: 10.1111/j.1461-9563.2009.00451.x.

Moser, W.K., E.L. Barnard, R.F. Billings, S.J. Crocker, M.E. Dix, A.N. Gray, G.G. Ice, M.S. Kim, R. Reid, S.U. Rodman and W.H. McWilliams. 2009. Impacts of nonnative invasive species on US forests and recommendations for policy and management. J. For. 107(6): 320-327.

Muirhead, J.R., B. Leung, C. Overdijk, D.W. Kelly, K. Nandakumar, K.R. Marchant and H.J. MacIsaac. 2006. Modelling local and long-distance dispersal of invasive emerald ash borer Agrilus planipennis (Coleoptera) in North America. Divers. Distrib. 12(1): 71-79. doi: 10.1111/j.1366-9516.2006.00218.x.

Neighborwoods. 2015. Web. Accessed 1 May 2015. http://neighbourwoods.org/.

Nisbet, D.J. 2014. Indirect ecological impacts of emerald ash borer and associated ash decline in southern Ontario riparian areas: risks to aquatic communities. MSc Thesis. School of Environmental Sciences, University of Guelph, Guelph, Ontario.

Paiero, S.M., M.D. Jackson, A. Jewiss-Gaines, T. Kimoto, B.D. Gill and S.A. Marshall. 2012. Field guide to the jewel beetles (Coleoptera: Buprestidae) of northeastern North America. Canadian Food Inspection Agency, Ottawa, Ontario, Canada. 
Poland, T.M., D.G. McCullough, A.C. Anulewicz, P. Lewis and D. Cappaert. 2011. Evaluation of double-decker traps for emerald ash borer (Coleoptera: Buprestidae). J. Econ. Entomol. 104(5): 517-531. doi: $10.1603 /$ ec11101.

Prasad, A.M., L.R. Iverson, M.P. Peters, J.M. Bossenbroek, S.N. Matthews, T. Davis Sydnor and M.W. Schwartz. 2009. Modeling the invasive emerald ash borer risk of spread using a spatially explicit cellular model. Landsc. Ecol. 25(3): 353-369. doi: 10.1007/s10980009-9434-9.

Ryall, K. 2015. Detection and sampling of emerald ash borer (Coleoptera: Buprestidae) infestations. Can. Entomol. in press.

Ryall, K.L. and T.A. Scarr. 2012. Workshop proceedings: Emerald ash borer - New tools in the toolbox November 22, 2011, Royal Botanical Gardens, Burlington, Ontario, Canada. Canada-Ontario Invasive Species Centre, Sault Ste. Marie, Ontario, Canada.

Ryall, K.L, J.G. Fidgen and J.J. Turgeon. 2011. Detectability of the emerald ash borer (Coleoptera: Buprestidae) in asymptomatic urban trees by using branch samples. Environ. Entomol. 40: 679-688. doi: 10.1603/en10310.

Ryall, K.L., J.G. Fidgen, P.J. Silk and T.A. Scarr. 2013. Efficacy of the pheromone (3 Z)-lactone and the host kairomone (3 Z )-hexenol at detecting early infestation of the emerald ash borer, Agrilus planipennis. Entomol. Exp. Appl. 147(2): 126-131. doi: 10.1111/eea.12052. Scarr, T. 2012. Components of an emerald ash borer management plan. In K.L. Ryall and T.A. Scarr (eds.). Workshop proceedings: Emerald ash borer - New tools in the toolbox November 22, 2011, Royal Botanical Gardens, Burlington, Ontario, Canada. pp. 2-7. Canada-Ontario Invasive Species Centre, Sault Ste. Marie, Ontario, Canada.
Siegert, N.W., D.G. McCullough, A.M. Liebhold and F.W. Telewski. 2014. Dendrochronological reconstruction of the epicentre and early spread of emerald ash borer in North America. Divers. Distrib. 20(7): 847-858. doi: 10.1111/ddi.12212.

Streit, M., T. Scarr and L. Farintosh. 2012. Preparing for emerald ash borer: A landownders guide to managing ash forests. Ontario Ministry of Natural Resources, Sault Ste. Marie, Ontario, Canada.

Sydnor, T.D., M. Bumgardner and A. Todd. 2007. The potential economic impacts of emerald ash borer (Agrilus planipennis) on Ohio, U.S. communities. Arboric. Urban For. 33: 48-54.

Tanis, S.R. and D.G. McCullough. 2012. Differential persistence of blue ash and white ash following emerald ash borer invasion. Can. J. For. Res. 42(8): 1542-1550. doi: 10.1139/x2012-103.

Taylor, R.A.J., L.S. Bauer, T.M. Poland and K.N. Windell. 2010. Flight performance of Agrilus planipennis (Coleoptera: Buprestidae) on a flight mill and in free flight. J. Insect Behav. 23(2): 128-148. doi: 10.1007/s10905-010-9202-3.

Wei, X., D. Reardon, Y. Wu and J.-H. Sun. 2004. Emerald ash borer, Agrilus planipennis Fairmaire (Coleoptera: Buprestidae), in China: a review and distribution survey. Acta Entomol. Sin. 47(5): 679-685.

Whitehill, J.G.A., C. Rigsby, D. Cipollini, D.A. Herms and P. Bonello. 2014. Decreased emergence of emerald ash borer from ash treated with methyl jasmonate is associated with induction of general defense traits and the toxic phenolic compound verbascoside. Oecologia 176(4): 1047-59. doi: 10.1007/s00442-014-3082-8.

Yemshanov, D., F.H. Koch, D. Barry Lyons, M. Ducey and K. Koehler. 2012. A dominance-based approach to map risks of ecological invasions in the presence of severe uncertainty. Divers. Distrib. 18(1): 33-46. doi: 10.1111/j.1472-4642.2011.00848.x. 